\title{
Aortic volume determines global end- diastolic volume measured by transpulmonary thermodilution
}

\author{
Aleksej Akohov ${ }^{1}$, Christoph Barner ${ }^{1}$, Steffen Grimmer ${ }^{1,3}$, Roland CE Francis ${ }^{1}$ and Stefan Wolf ${ }^{2^{*}}$ (D)
}

\author{
* Correspondence: stefan.wolf@ \\ charite.de \\ ${ }^{2}$ Department of Neurosurgery, \\ Charité Campus Mitte, Charité - \\ Universitätsmedizin Berlin, Freie \\ Universität Berlin, \\ Humboldt-Universität zu Berlin, and \\ Berlin Institute of Health, Berlin, \\ Germany \\ Full list of author information is \\ available at the end of the article
}

\begin{abstract}
Background: Global end-diastolic volume (GEDV) measured by transpulmonary thermodilution is regarded as indicator of cardiac preload. A bolus of cold saline injected in a central vein travels through the heart and lung, but also the aorta until detection in a femoral artery. While it is well accepted that injection in the inferior vena cava results in higher values, the impact of the aortic volume on GEDV is unknown. In this study, we hypothesized that a larger aortic volume directly translates to a numerically higher GEDV measurement.

Methods: We retrospectively analyzed data from 88 critically ill patients with thermodilution monitoring and who did require a contrast-enhanced thoracoabdominal computed tomography scan. Aortic volumes derived from imaging were compared with GEDV measurements in temporal proximity.

Results: Median aortic volume was $194 \mathrm{ml}$ (interquartile range 147 to $249 \mathrm{ml}$ ). Per milliliter increase of the aortic volume, we found a GEDV increase by $3.0 \mathrm{ml}(95 \% \mathrm{Cl}$ 2.0 to $4.1 \mathrm{ml}, p<0.001)$. In case a femoral central venous line was used for saline bolus injection, GEDV raised additionally by $2.1 \mathrm{ml}(95 \% \mathrm{Cl} 0.5$ to $3.7 \mathrm{ml}, p=0.01)$ per $\mathrm{ml}$ volume of the vena cava inferior. Aortic volume explained $59.3 \%$ of the variance of thermodilution-derived GEDV. When aortic volume was included in multivariate regression, GEDV variance was unaffected by sex, age, body height, and weight.
\end{abstract}

Conclusions: Our results suggest that the aortic volume is a substantial confounding variable for GEDV measurements performed with transpulmonary thermodilution. As the aorta is anatomically located after the heart, GEDV should not be considered to reflect cardiac preload. Guiding volume management by raw or indexed reference ranges of GEDV may be misleading.

Keywords: Aorta, Aortic volume, Global end-diastolic volume, GEDV, GEDVI, Transpulmonary thermodilution, Vena cava, Vena cava volume

\section{Introduction}

Transpulmonary thermodilution is commonly used and recommended in current guidelines for the management of critically ill patients with cardiovascular instability to assess cardiac output $(\mathrm{CO})$ and volume status $[1,2]$. The parameter global end-diastolic volume (GEDV), a hypothetical volume assuming all cardiac chambers being simultaneously in diastole, is considered to reflect cardiac preload [3]. Michard et al. described that GEDV indexed to body surface area (GEDVI) more adequately predicted volume responsiveness 
in patients with septic shock compared with the central venous pressure [4]. In a prospective randomized trial, Goepfert et al. found that guidance with an algorithm including GEDVI reduced complications and length of ICU stay in patients after cardiac surgery [5]. Kaneko et al. identified GEDVI as an important contributor to elevated extravascular lung water (EVLW) in patients with ARDS [6].

However, it was recently shown that GEDVI did not reflect even markedly enlarged left-ventricular end-diastolic volumes measured by cardiac angiography [7]. Furthermore, reference values for GEDVI proposed by expert opinion vary and a reference range applicable to all subjects was repeatedly questioned [8-10]. A meta-analysis including 64 studies recognized significantly higher mean GEDVI in septic patients compared with patients undergoing major surgery and concluded the need to adapt therapeutic targets for different patient populations [8]. Huber et al. noticed a dependence of GEDV on age, sex, body height, and body weight in patients in a medical intensive care unit and proposed sexspecific formulas to alleviate the problem of indexation [9]. A prospective observational trial found a large inter-individual variability of GEDV and GEDVI and hypothesized that the aortic volume might be the source of the observed heterogeneity [10]. This potential explanation was based on the fact that the cold saline bolus injected for measurement must transit the aorta to reach the temperature detector placed in a femoral artery. It is well known that the aortic size increases with age and is sex dependent [11]. Patients with an aortic aneurysm present with higher GEDVI values [12]. However, neither the theoretical derivation nor contemporary reviews of GEDV and GEDVI measured by transpulmonary thermodilution do consider the aortic volume [13-16].

In the present study, we investigate the hypothesis of a relationship between aortic volume and GEDV.

\section{Methods}

\section{Study population}

The study was approved by the Ethics Committee of Charite - Universitätsmedizin Berlin (vote EA 1/084/13). The study was performed at the Interdisciplinary Neurointensive Care Unit of Charité - Universitätsmedizin Berlin at Charité Campus Virchow, with inclusion from January 2009 to December 2016. We identified subjects who had monitoring with transpulmonary thermodilution implemented. Additionally, patients were required to have received a contrast-enhanced CT scan of the thorax and abdomen, either as screening for injury after trauma, but also in search of a septic focus. We selected patients with mechanical ventilation and an arbitrarily chosen time difference of maximum $12 \mathrm{~h}$ between $\mathrm{CT}$ scan and thermodilution measurement (Fig. 1).

\section{Transpulmonary thermodilution measurements}

As usual in transpulmonary thermodilution, iced saline was injected via a central venous line and the resulting thermal signal was detected by a thermodilution catheter (PVPK 2015 L20-A) in a femoral artery. Both catheters were connected to a PiCCO2 monitor (Pulsion Medical Systems, Munich, Germany).

Cardiac output $(\mathrm{CO})$ is derived from the area under the curve by the StewartHamilton formula [17]. The thermal signal may be characterized further by mean transit time (MTt) and downslope time (DSt), the inverse of its rate of decay [15, 18]. MTt 


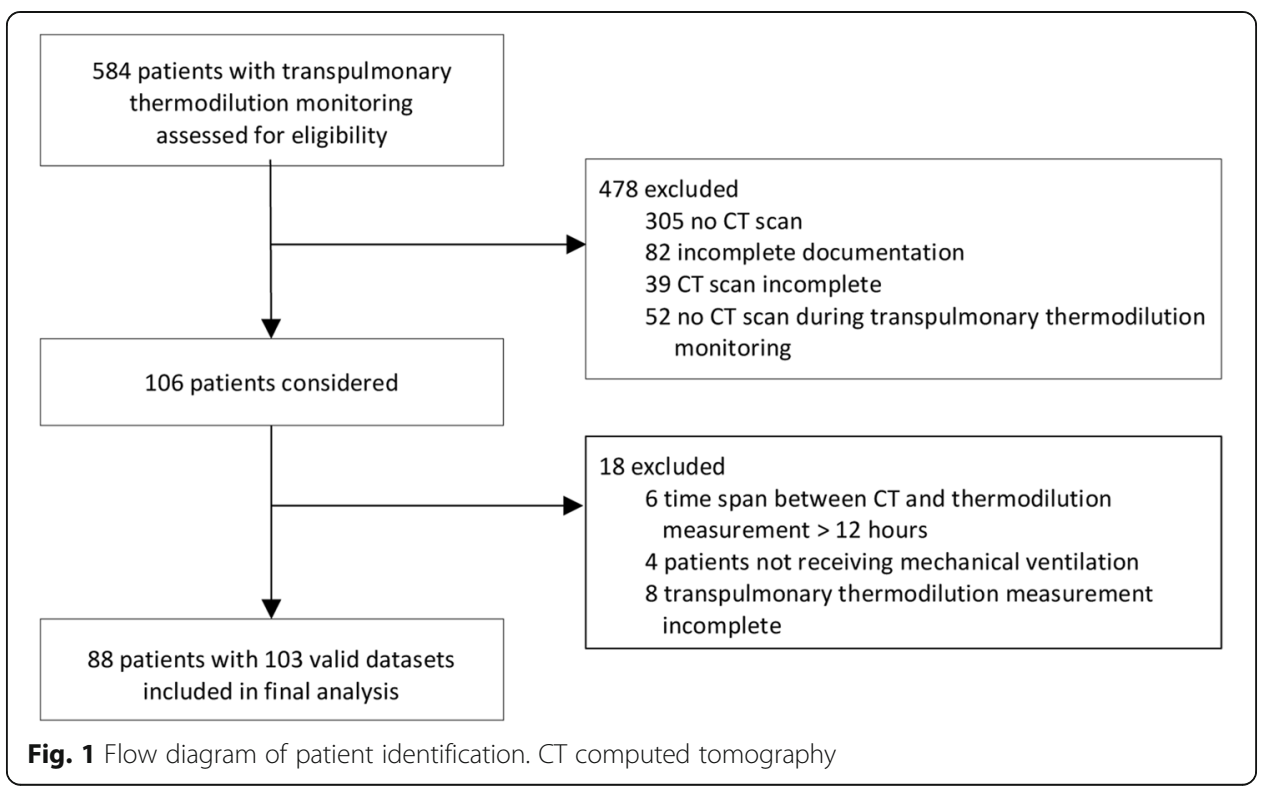

times $\mathrm{CO}$ equals the distribution volume of thermal indicator, the intrathoracic thermal volume (ITTV). In a series of sequentially traversed volumes, the largest one determines the DSt [13]. In case of transpulmonary thermodilution, the largest thermal compartment is assumed to be the lung, resulting in the pulmonary thermal volume PTV = $\mathrm{CO} \times$ DSt. The difference between ITTV and PTV equals the GEDV, which may be calculated as:

$$
\mathrm{GEDV}=(\mathrm{CO} \times \mathrm{MTt})-(\mathrm{CO} \times \mathrm{DSt})
$$

CO, MTt, DSt, GEDV, and EVLW were obtained from the average of a series of at least three venous injections of $20 \mathrm{ml}$ of iced saline [19], with outliers $( \pm 3 \mathrm{SD}$ ) discarded. All thermodilution data were extracted from archived log files of the PiCCO2 devices. As suggested by the manufacturer, GEDVI was calculated by dividing GEDV by body surface area based on predicted body weight.

Of note, in transpulmonary thermodilution, the volume between the aortic valve and the detector in a femoral artery is obviously traversed by the cold indicator bolus. Therefore, measured GEDV may be split in a venous volume, a central part-the volume of interest as surrogate for cardiac preload-and the aortic volume:

$$
\mathrm{GEDV}_{\text {measured }}=\mathrm{GEDV}_{\text {venous }}+\mathrm{GEDV}_{\text {central }}+\mathrm{GEDV}_{\text {aortic }}
$$

The venous part may be assumed to be zero in case of a central venous line in the superior vena cava. However, the aortic part of GEDV remains inevitably included in transpulmonary thermodilution measurements.

\section{Image analysis}

Contrast-enhanced thoracic-abdominal CT scans were retrieved from the Picture Archive and Communication System GEPACS (Centricity PACS 3.2 RA 1000 Workstation, GE Healthcare, Chicago, USA). Post-processing of the images was performed with Osirix ${ }^{\circ}$ MD 6.5.2 (Pixmeo SARL, Geneva, Switzerland). The aorta was identified on axial slides and marked manually as region of interest (ROI) [20, 21]. The resulting 
sequence of interconnected ROIs together with the slice width was used for volume calculation, with the left coronary artery and the tip of the transpulmonary thermodilution catheter in the femoral artery as longitudinal boundaries. This reconstructed volume is referred to as "aortic volume" (Fig. 2, Additional files 1 and 2). For length determination, a central path was marked manually. Diameters were calculated from cross-sectional areas assuming circular boundaries. When a femoral central venous catheter was present, reconstruction of the volume of the inferior vena cava was performed likewise, using the tip of the catheter and the right atrium as boundaries. In patients with a subclavian or jugular central venous catheter, the correct position of its tip is at the entrance of the right atrium. Consequentially, the additional volume of the vena cava relevant for thermodilution measurements was assumed to be zero.

\section{Statistical analysis}

Statistical computation was performed with R 3.4.3 (R Core Team, R Software Foundation, Vienna, Austria, 2018). Results are given as median and interquartile range (IQR) or with
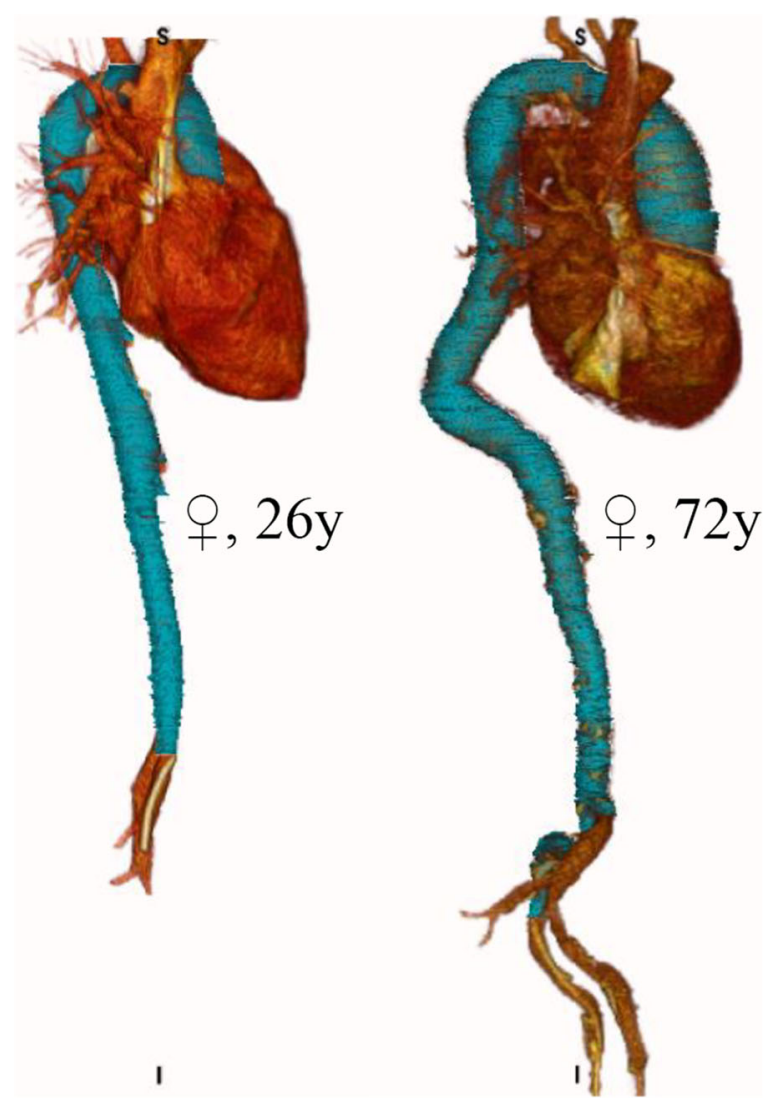

Fig. 2 Representative reconstructed three-dimensional sagittal computed tomography images of the heart and the aorta. Left side is from a 26-year-old female with meningoencephalitis and septic shock, $59 \mathrm{~kg}, 170$ $\mathrm{cm}$. GEDV $502 \mathrm{ml}$, GEDVI $293 \mathrm{ml} / \mathrm{m}^{2}$. Right side shows data from a 72-year-old female with aneurysmal subarachnoid hemorrhage, $165 \mathrm{~cm}, 78 \mathrm{~kg}$. GEDV $1263 \mathrm{ml}$, GEDVI $787 \mathrm{ml} / \mathrm{m}^{2}$. 3D rotational images are provided in the electronic supplements (see Additional files 1 and 2). Aortic volume, defined as the volume of the aorta between the left coronary artery and the tip of the femoral catheter, is visualized in blue. Proportions reflect real dimensions. Note the difference in size and shape of the aortic volume 
mean and corresponding 95\% confidence intervals (95\% CI), as appropriate. No imputation was performed for missing data. Regression analysis was performed with robust linear regression (R package robustbase, version 0.93-5) to account for heteroscedasticity and skewness. Biometric parameters (age, sex, body height, and weight) were investigated simultaneously to account for partial correlation using multivariate models. Mixed effect models to correct for repeated CT measurements in few patients proved not to be superior by the minimized Akaike Information Criterion (AIC) [22]. Therefore, in favor of parsimony, all measurements were regarded as independent. Explained variance is given by adjusted $R^{2} . p$ values less than 0.05 were considered significant.

\section{Results}

\section{Data description}

We identified 103 CT scans in 88 patients meeting the inclusion criteria (Fig. 1). Demographic data of the patients are shown in Table 1. ICU scores, vasoactive drugs, ventilation parameters, and location of central venous catheters are shown in Table 2. Included in this table are time differences and fluid balance between CT scanning and thermodilution measurements. Data of CT scans and transpulmonary thermodilution measurements are given in Table 3.

\section{Aortic volume}

Median aortic volume, measured from the aortic valve to the tip of the femoral artery catheter, was $158 \mathrm{ml}$ (IQR 126 to $207 \mathrm{ml}$ ) in females and $213 \mathrm{ml}$ (IQR 169 to $287 \mathrm{ml}$ ) in males $(p<0.001)$. Aortic volume increased by $2.3 \mathrm{ml}$ (95\% CI 1.7 to $2.8 \mathrm{ml}, p<0.001$ ) per year of patient age. Aortic volume showed no significant relationship to body height ( $p>0.05)$, but increased by $1.2 \mathrm{ml}(95 \% \mathrm{CI} 0.3$ to $2.2 \mathrm{ml}, p=0.009)$ per $\mathrm{kg}$ of patient body weight. Measurements of aortic volume had a coefficient of repeatability of $2.1 \%$.

Table 1 Patient characteristics

\begin{tabular}{llll}
\hline Patients & All & Female & Male \\
\hline$n(\%)$ & $88(100)$ & $32(36.4)$ & $56(63.6)$ \\
Age, year & $57(42-68)$ & $52(40-70)$ & $59(45-67)$ \\
Weight, kg & $80(70-90)$ & $65(60-80)$ & $85(75-94)$ \\
Body height, $m$ & $1.74(1.68-1.80)$ & $1.65(1.60-1.70)$ & $1.8(1.73-1.83)$ \\
BMl, kg/m ${ }^{2}$ & $26(23-29)$ & $25(22-29)$ & $26(24-29)$ \\
Reason for ICU admission, $n$ (\%) & & & \\
$\quad$ Traumatic brain injury & $22(25.0)$ & $2(6.3)$ & $20(35.7)$ \\
$\quad$ Spontaneous intracranial hemorrhage & $16(18.2)$ & $1(3.1)$ & $15(26.8)$ \\
$\quad$ Aneurysmal subarachnoid hemorrhage & $14(15.9)$ & $9(28.1)$ & $5(8.9)$ \\
Infections of the central nervous system & $8(9.1)$ & $5(15.6)$ & $3(5.4)$ \\
Sepsis & $6(6.8)$ & $4(12.5)$ & $2(3.6)$ \\
Infarct & $6(6.8)$ & $2(6.3)$ & $4(7.1)$ \\
$\quad$ Tumor & $4(4.5)$ & $4(12.5)$ & $0(0)$ \\
Respiratory failure & $3(3.4)$ & $0(0)$ & $3(5.4)$ \\
$\quad$ Other & $9(10.2)$ & $5(15.6)$ & $4(7.1)$ \\
In-hospital mortality, $n$ (\%) & $39(44.3)$ & $16(50)$ & $23(41.1)$ \\
\hline BMI body mass index, ICU intensive care unit. Data are presented as median (interquartile range) or number (frequency \\
in percent)
\end{tabular}


Table 2 Clinical data at time of CT and thermodilution measurement, respectively

\begin{tabular}{|c|c|c|c|}
\hline & All & Female patients & Male patients \\
\hline$n(\%)$ & $103(100)$ & $38(36.9)$ & $65(63.1)$ \\
\hline \multicolumn{4}{|l|}{ ICU scoring } \\
\hline APACHE ॥ & $26(21-31)$ & $27(20-32)$ & $25(22-30)$ \\
\hline SAPS $\|$ & $56(45-67)$ & $54(43-63)$ & $58(46-68)$ \\
\hline SOFA & $11(9-13)$ & $11(9-14)$ & $11(9-13)$ \\
\hline \multicolumn{4}{|l|}{ Patients receiving catecholamines, $n(\%)$} \\
\hline Adrenaline & $4(3.9)$ & $1(2.6)$ & $3(4.6)$ \\
\hline Dobutamine & $7(6.8)$ & $2(5.3)$ & $5(7.7)$ \\
\hline Norepinephrine & $101(98.1)$ & $37(97.4)$ & $64(98.5)$ \\
\hline Norepinephrine dose at time of TD measurement, $\mu \mathrm{g} / \mathrm{kg} / \mathrm{min}$ & $0.27(0.11-0.52)$ & $0.32(0.12-0.53)$ & $0.20(0.11-0.47)$ \\
\hline Norepinephrine dose at time of $\mathrm{CT}, \mu \mathrm{g} / \mathrm{kg} / \mathrm{min}$ & $0.26(0.11-0.50)$ & $0.30(0.11-0.51)$ & $0.25(0.11-0.50)$ \\
\hline \multicolumn{4}{|l|}{ Patients receiving another cardiovascular agent, $n(\%)$} \\
\hline Enoximone & $10(9.7)$ & $3(7.9)$ & $7(10.8)$ \\
\hline Nitroglycerine & $3(2.9)$ & $2(5.3)$ & $1(1.5)$ \\
\hline Vasopressin & $2(1.9)$ & $1(2.6)$ & $1(1.5)$ \\
\hline Patients receiving more than one cardiovascular agent, $\mathrm{n}(\%)$ & $21(20.4)$ & $7(18.4)$ & $14(21.5)$ \\
\hline \multicolumn{4}{|l|}{$\begin{array}{l}\text { Parameters of mechanical ventilation at time of } \\
\text { thermodilution measurement }\end{array}$} \\
\hline PEEP, $\mathrm{mmHg}$ & $10(9-13)$ & $10(9-12)$ & $10(9-13)$ \\
\hline$f, 1 / \min$ & $21(18-25)$ & $20(17-24)$ & $22(18-26)$ \\
\hline $\mathrm{VT}, \mathrm{I}$ & $0.49(0.40-0.55)$ & $0.41(0.33-0.49)$ & $0.51(0.46-0.57)$ \\
\hline \multicolumn{4}{|l|}{ Parameters of mechanical ventilation at time of $\mathrm{CT}$} \\
\hline PEEP, $\mathrm{mmHg}$ & $10(9-13)$ & $10(9-13)$ & $11(9-13)$ \\
\hline f, $1 / \min$ & $21(17-25)$ & $21(17-25)$ & $22(18-25)$ \\
\hline$V T, I$ & $0.49(0.40-0.55)$ & $0.40(0.36-0.49)$ & $0.52(0.46-0.56)$ \\
\hline $\begin{array}{l}\text { Time span between CT and thermodilution } \\
\text { measurement, hours }\end{array}$ & $1(-1-3)$ & $0(-1-3)$ & $1(-1-3)$ \\
\hline $\begin{array}{l}\text { Fluid balance between } \mathrm{CT} \text { and thermodilution } \\
\text { measurement, } \mathrm{ml}\end{array}$ & $-10(-198-258)$ & $0(-94-434)$ & $-31(-289-128)$ \\
\hline Continuous veno-venous hemodialysis, $n(\%)$ & $20(19.4)$ & $6(15.8)$ & $14(21.5)$ \\
\hline \multicolumn{4}{|l|}{ CVC position } \\
\hline V. jugularis, $n(\%)$ & $48(46.6)$ & $20(52.6)$ & $28(43.1)$ \\
\hline V. subclavia, $n(\%)$ & $40(38.8)$ & $13(34.2)$ & $27(41.5)$ \\
\hline V. femoralis, $n(\%)$ & $15(14.6)$ & $5(13.2)$ & $10(15.4)$ \\
\hline Aortic aneurysm, $n(\%)$ & $2(1.9)$ & $0(0)$ & $2(3.1)$ \\
\hline Status post-OAR or EVAR, $n(\%)$ & $5(4.9)$ & $0(0)$ & $5(7.7)$ \\
\hline
\end{tabular}

APACHE I/ acute physiology and chronic health evaluation II, CVC central venous catheter, EVAR endovascular aortic aneurysm repair, ICU intensive care unit, OAR open aortic repair, SAPS // simplified acute physiology score, SOFA sequential organ failure assessment. Data are presented as median (interquartile range) or number (frequency in percent)

\section{Measurements of inferior vena cava}

Fifteen measurements were performed with a femoral central venous line. In two patients, we were unable to unequivocally identify the upper boundary of the vena cava at the level of the diaphragm due to enlarged hepatic veins. Thus, an accurate and reproducible volume calculation was impossible. In the remaining 13 patients, median volume of the inferior vena cava was $127 \mathrm{ml}$ (IQR 93 to $155 \mathrm{ml}$ ). Analysis of relationships with age, sex, height, and weight was not considered meaningful due to the low number of patients. 
Table 3 Aortic and vena cava length and volume derived from CT scans and physiologic values from transpulmonary thermodilution measurements

\begin{tabular}{llll}
\hline & All & Female patients & Male patients \\
\hline$n$ (\%) & $103(100)$ & $38(36.9)$ & $65(63.1)$ \\
Aortic length, cm & $55.2(51.0-60.2)$ & $50.8(47.5-56.6)$ & $56.4(53.8-61.5)$ \\
Aortic volume, ml & $194(147-249)$ & $158(126-207)$ & $213(169-287)$ \\
Vena cava length (femoral CVC), cm & $32.1(27.8-33.4)$ & $32.5(31.1-38.1)$ & $28.6(21.5-32.6)$ \\
Vena cava volume (femoral CVC), ml & $127(93-155)$ & $162(150-188)$ & $98(77-122)$ \\
HR, 1/min & $86(74-103)$ & $84(74-100)$ & $89(71-105)$ \\
MAP, mmHg & $83(73-93)$ & $84(74-96)$ & $83(72-92)$ \\
CO, I/min & $6.4(5.3-7.8)$ & $5.6(4.9-6.8)$ & $6.8(5.8-8.2)$ \\
Cl, I/min/m² & $3.3(2.8-4.0)$ & $3.1(2.6-3.9)$ & $3.4(2.9-4.2)$ \\
GEDV, ml & $1306(1104-1569)$ & $1129(990-1283)$ & $1437(1169-1658)$ \\
GEDVl, ml/m² & $730(627-871)$ & $709(627-840)$ & $738(628-894)$ \\
EVLW, ml & $603(510-781)$ & $540(462-619)$ & $649(528-829)$ \\
EVLWl, ml/kg & $9.7(7.8-11.6)$ & $9.9(8.7-11.5)$ & $9.3(7.7-11.7)$ \\
MTt, s & $20.9(17.7-27.3)$ & $19.4(17.4-27.3)$ & $21.1(17.9-27.4)$ \\
DSt, s & $8.4(7.2-11.3)$ & $8.4(7.2-10.9)$ & $8.5(7.2-11.3)$ \\
\hline
\end{tabular}

Cl cardiac index, CO cardiac output, CVC central venous catheter, EVLW extravascular lung water, EVLWI extravascular lung water index, GEDV global end-diastolic volume, GEDVI global end-diastolic volume index, HR heart rate, MAP mean arterial pressure, DSt down slope time, MTt mean transit time. All data is presented as median (interquartile range)

\section{Dependencies of GEDV and GEDVI on biometric parameters}

Median GEDV in all patients was $1306 \mathrm{ml}$ (IQR 1104 to $1569 \mathrm{ml}$ ). Median GEDVI was $730 \mathrm{ml} / \mathrm{m}^{2}$ (IQR 627 to $871 \mathrm{ml} / \mathrm{m}^{2}$ ).

GEDV increased by $7.4 \mathrm{ml}$ (95\% CI 4.1 to $10.7 \mathrm{ml}, p<0.001)$ per year of patient age. Per kilogram increase in body weight, GEDV increased by $5.2 \mathrm{ml}$ (95\% CI 1.7 to $8.6 \mathrm{ml}, p=0.003)$. After correction for age and weight, GEDV showed no significant dependency on height and sex. These relationships persisted after indexing GEDV by body surface area based on predicted body weight. GEDVI increased by $4.2 \mathrm{ml} / \mathrm{m}^{2}$ (95\% CI 2.3 to $6.2 \mathrm{ml} / \mathrm{m}^{2}, p<0.001$ ) per year of age and by $2.8 \mathrm{ml} / \mathrm{m}^{2}$ ( $95 \%$ CI 0.9 to $4.7 \mathrm{ml} / \mathrm{m}^{2}, p=0.004$ ) per $\mathrm{kg}$ body weight, while height and sex showed no significant relationship.

In patients with a femoral central venous line, GEDV was $438 \mathrm{ml}$ (95\% CI 235 to 641 $\mathrm{ml}, p<0.001)$ larger than in patients with jugular or subclavian central venous catheter. Likewise, GEDVI was $230 \mathrm{ml} / \mathrm{m}^{2}$ (95\% CI 89 to $\left.370 \mathrm{ml} / \mathrm{m}^{2}, p=0.002\right)$ larger in patients with a femoral venous line.

Time differences, fluid balances, changes in ventilator settings, or the level of vasoactive drugs between thermodilution measurements and CT scans were without significant impact on GEDV ( $p>0.05$ for each comparison). GEDV measurements showed a coefficient of repeatability of $4.3 \%$.

\section{Dependence of GEDV on central venous and aortic volume}

A total of $38.4 \%$ of the variance of GEDV was explained by patient-specific biometric characteristics including age, sex, body weight, and body height. We then sequentially added the volumes of either the vena cava, the aorta, or both to this initial model. 
Inclusion of the volume of the vena cava raised the explained variance of GEDV to $47.8 \%$. After adding the aortic volume to the basic model instead of the volume of the vena cava, explained GEDV variance was 59.3\%. Combining both aortic and venous volume led to an explained variance of GEDV of $63.8 \%$. In each model where the aortic volume was included, all biometric parameters lost their significance (Table 4).

\section{Analysis of GEDV components}

In the final regression model including both aortic volume and the volume of the vena cava, GEDV increased by $3.0 \mathrm{ml}$ ( $95 \%$ CI 2.0 to $4.1 \mathrm{ml}, p<0.001)$ per $\mathrm{ml}$ of aortic volume and by $2.1 \mathrm{ml}(95 \%$ CI 0.5 to $3.7 \mathrm{ml}, p=0.01$ ) per $\mathrm{ml}$ of vena cava volume. Plotting the data suggested a linear relationship between the aortic volume and GEDV (Fig. 3).

Measured GEDV consists of a "venous," a "central," and an "aortic" part (see Methods). Assuming the linear relationships found above allowed for estimation of single proportions of GEDV. The aortic part was in median 49\% (IQR 40 to 58\%) of measured GEDV. In case of a femoral central venous line, the venous part estimated in median to $14 \%$ (IQR 14 to $17 \%$ ). The central part was in median 50\% (IQR 40 to 57\%) of measured GEDV. The central and venous parts did not depend on biometric parameters, while the aortic part had significant relationships with age and weight $(p<0.001$ and $p=0.009$, respectively).

To get further insight, we examined the influence of aortic volume on the different variables required for GEDV calculation: MTt, DSt, and CO. The largest impact was on MTt, with $3.5 \mathrm{~s}$ (95\% CI 1.4 to $5.5 \mathrm{~s}, p=0.001)$ per $100 \mathrm{ml}$ of aortic volume. Additionally, MTt showed a hyperbolic decline with raising values of $\mathrm{CO}(p<0.001)$. CO was larger in patients with higher aortic volume, $0.5 \mathrm{l} / \mathrm{min}(95 \% \mathrm{CI} 0$ to $1 \mathrm{l} / \mathrm{min}, p=0.041)$ per $100 \mathrm{ml}$ aortic volume. DSt enlarged by $0.8 \mathrm{~s}(95 \% \mathrm{CI} 0$ to $1.7 \mathrm{~s}, p=0.048)$ per $100 \mathrm{ml}$ aortic volume.

\section{Discussion}

As main finding, we confirmed the hypothesized relationship between GEDV and aortic volume. Aortic volume determines the value of GEDV to a larger extent than any biometric parameter, including a patient's age, sex, body weight, and height.

Table 4 Statistical significance of confounding variables for GEDV

\begin{tabular}{lllll}
\hline Statistical model & $\begin{array}{l}\text { (1) Basic model: biometric } \\
\text { descriptors }\end{array}$ & $\begin{array}{l}\text { (2) Basic model + } \\
\text { V. cava }\end{array}$ & $\begin{array}{l}\text { (3) Basic model } \\
+ \text { aorta }\end{array}$ & $\begin{array}{l}\text { (4) Basic model + aorta } \\
+ \text { V. cava }\end{array}$ \\
\hline Age & $p<0.001$ & $p<0.001$ & $p>0.05$ & $p>0.05$ \\
Male sex & $p>0.05$ & $p>0.05$ & $p>0.05$ & $p>0.05$ \\
Height & $p>0.05$ & $p>0.05$ & $p>0.05$ & $p>0.05$ \\
Weight & $p=0.003$ & $p=0.002$ & $p>0.05$ & $p>0.05$ \\
Aortic volume & & $p=0.003$ & $p<0.001$ & $p<0.001$ \\
Vena cava volume & & $48 \%$ & $59 \%$ & $p=0.009$ \\
Explained variance & $38 \%$ & $p<0.001$ & $p<0.001$ & $p<0.001$ \\
$\begin{array}{l}\text { Difference to } \\
\text { previous model }\end{array}$ & & & &
\end{tabular}

Multivariate statistical models investigate (1) the dependence of GEDV values on age, male sex, height, and body weight (basic model); (2) the biometric parameters from the basic model and additionally the volume of the vena cava; (3) the parameters from the basic model and additionally the aortic volume; and (4) the parameters from the basic model with biometric descriptors and both vena cava volume and aortic volume. Values in italics indicate significance 


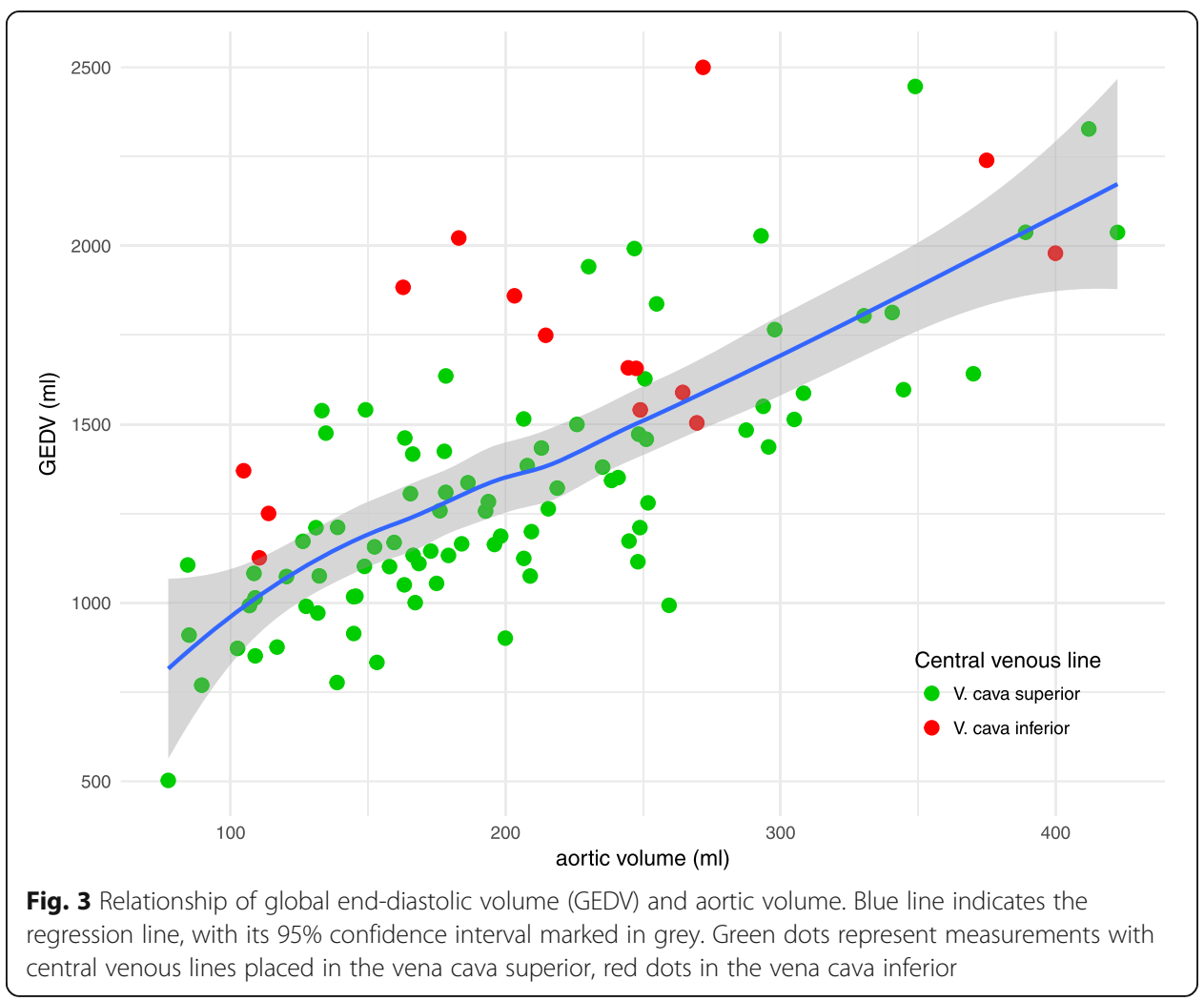

\section{Relevance of central venous and aortic volumes for GEDV measurement}

It is well accepted and confirmed by our data that femoral central venous lines should be accounted for when interpreting GEDV measurements [23-25]. However, our results show that the aortic volume had an even larger, predominant influence by explaining roughly $60 \%$ of GEDV variance. As the aortic volume is anatomically placed after the heart, our findings challenge the view of GEDV as a cardiac preload parameter.

It is important to mention that our measurements of the aortic diameter, length, and volume as well as estimated aortic mean transit times are in line with published data $[11,26-30]$.

\section{Analysis of influences on thermal volume}

Contrast bolus traverse through the aorta led to a larger increase in GEDV than expected by considering plain aortic volume. Two interacting causes may be suggested. First, theory of single-indicator transpulmonary thermodilution requires a closed circulation between injection and detection site [14]. Thoracic and abdominal branches of the aorta invalidate this prerequisite. Second, the flow along the aorta is not laminar but turbulent and helical [31-33]. Both potential causes would challenge the assumption of CO times MTt being equal to the traversed volume.

In patients with a femoral central venous line, similar considerations concerning the necessary prerequisites apply. The vena cava inferior has influx from abdominal and hepatic veins, thus not resembling a closed system as required for calculation of GEDV from the thermodilution curve. 


\section{Concerns against indexing GEDV}

Indexing of a physiological parameter intends to remove inter-individual variations to facilitate comparison between patients and derive normal ranges. From a mathematical point of view, indexing represents a linear regression, which may be defined by two points only. One is the mean of the parameter to be indexed and the mean of the index. The second point is the origin, where both the parameter and the index are zero, usually far away from physiologic ranges. Therefore, the slope of the regression line is mainly determined by the origin as a gross outlier. This may lead to the removal of existing correlations, but also generation of correlations not present in the original data [34-36].

Obviously, indexing GEDV can be performed numerically, but this does not imply that the result is meaningful. The relevant confounder of GEDV, the aortic volume, is cumbersome to achieve and usually not known. Therefore, indexing by aortic volume is not applicable. In current practice, GEDV indexation is performed with predicted body surface area derived from height. In our data, height was no significant confounder. In contrast, a dependency of GEDV on age and weight was present before, but also after indexing by predicted body surface area. Furthermore, the central part of GEDV had no relationship with any biometric parameter, while the aortic part was dependent on age and weight. The ratio between both parts varies from patient to patient. The quest for reference ranges of GEDV is further complicated when femoral central venous lines are taken into account. Therefore, there is little to support a scientifically validated and clinically useful indexation.

\section{Clinical implications}

We interpret our data that the numeric value of GEDV reflects the intravascular volume status of a patient, with preload being a minor contributor and not the dominant part. Future, prospective work may address the impact of volume loading, vasopressors, or mechanical ventilation on venous, central, and aortic components of GEDV. It is likely that this impact is different on each component, given that a controlled volume loss affects the diameter of the vena cava more than that of the abdominal aorta [37]. However, current transpulmonary thermodilution technology does not allow to distinguish between the different parts of measured GEDV. Its value is partially dependent on the aortic volume, which is itself being associated with age, sex, and weight. As a consequence, any treatment decision aiming for standardized normal values of GEDV/GEDVI may be beneficial in one patient but detrimental in another. Variations between successive measurements may have clinical importance [4], but require further study, in our opinion.

\section{Limitations}

Missing knowledge of the effect size rendered planning of a prospective study impossible. However, electronic recording guaranteed data accuracy and we are unaware of any systematic bias concerning patient selection.

Our population was treated in a neurosurgical ICU. While this may be considered a limitation, we want to point out that subjects presented with hemodynamic instability due to various causes, were on vasopressors and required mechanical ventilation. In 
our opinion, this reflects a typical scenario where transpulmonary thermodilution monitoring may be applied.

Central venous lines used were multi-lumen catheters of different brands. Per clinical standard, we mount the venous thermistor for transpulmonary thermodilution on the side arm of the first 3-way stopcock on the distal lumen. Occasional use of a different ports or failure of correct placement of the catheter tip at the entrance of the right atrium in case of jugular or subclavian central venous lines may have induced a minor error we were unable to correct for.

\section{Conclusion}

We provide evidence that the aortic volume mainly accounts for the variability of GEDV measured by single-indicator transpulmonary thermodilution with a femoral arterial line. Therefore, GEDV should not be considered to reflect the cardiac preload status of a patient. Furthermore, we were unable to provide a scientific physiological rationale for indexing GEDV. As a consequence, guiding individual volume therapy by reference ranges of GEDV or GEDVI may be misleading.

\section{Supplementary information}

Supplementary information accompanies this paper at https://doi.org/10.1186/s40635-019-0284-8.

Additional file 1. 3-D rotational image of a 26 years old female with meningoencephalitis and septic shock, 170 $\mathrm{cm}, 59 \mathrm{~kg}$. Slice width $0.625 \mathrm{~mm}$. Aortic volume $77 \mathrm{ml}$, distance form aortic valve to femoral detector $41 \mathrm{~cm}, \mathrm{CO} 3.3$ I/min, MTt 17 s, GEDV 502 ml, GEDVI $293 \mathrm{ml} / \mathrm{m}^{2}$.

Additional file 2. 3-D sagittal rotational image of a 72 years old female with aneurysmal subarachnoid hemorrhage, $165 \mathrm{~cm}, 78 \mathrm{~kg}$. Slice width $0.625 \mathrm{~mm}$. Aortic volume $211 \mathrm{ml}$, distance from aortic valve to femoral detector $62 \mathrm{~cm}$, CO $3.3 \mathrm{l} / \mathrm{min}$, MTT $39 \mathrm{~s}$, GEDV $1263 \mathrm{ml}$, GEDVI $787 \mathrm{ml} / \mathrm{m}^{2}$.

\section{Acknowledgements}

The authors want to thank Willehad Boemke, M.D., and Raimund Helbok, M.D., for reviewing and commenting on the manuscript.

We acknowledge support from the German Research Foundation (DFG) and the Open Access Publication Funds of Charité - Universitätsmedizin Berlin.

\section{Authors' contributions}

Collection of data was done by A.A, S.G., and S.W. Analysis of data was done by A.A., C.B., and S.W. Interpretation of data was done by all authors. Drafting of the manuscript was done by A.A., C.B., and S.W. Conception of the study was done by S.W. Supervision of the study was done by R.F. and S.W. All authors read and approved the final manuscript.

\section{Funding}

We acknowledge support from the German Research Foundation (DFG) and the Open Access Publication Funds of Charité - Universitätsmedizin Berlin.

\section{Availability of data and materials}

Individual patient data supporting the conclusions is available in the Zenodo repository [38].

Ethics approval and consent to participate

The study was approved by the Ethics Committee of Charité Universitätsmedizin Berlin (vote EA 1/084/13).

\section{Consent for publication}

The study was a retrospective analysis of clinical routine data. Therefore, consent was not required.

\section{Competing interests}

The authors have no competing interests to declare.

\section{Author details}

${ }^{1}$ Department of Anesthesiology and Intensive Care Medicine (CCM/CVK), Charité - Universitätsmedizin Berlin, Freie Universität Berlin, Humboldt-Universität zu Berlin, and Berlin Institute of Health, Berlin, Germany. ${ }^{2}$ Department of Neurosurgery, Charité Campus Mitte, Charité - Universitätsmedizin Berlin, Freie Universität Berlin, Humboldt-Universität zu Berlin, and Berlin Institute of Health, Berlin, Germany. ${ }^{3}$ Department of Anesthesiology, Vivantes Klinikum Neukölln, Vivantes Netzwerk für Gesundheit, Berlin, Germany. 
Received: 3 September 2019 Accepted: 18 November 2019

Published online: 02 January 2020

\section{References}

1. Monnet X, Teboul J-L (2017) Transpulmonary thermodilution: advantages and limits. Crit Care Lond Engl 21:147. https:// doi.org/10.1186/s13054-017-1739-5

2. Marx G, Schindler AW, Mosch C et al (2016) Intravascular volume therapy in adults: guidelines from the Association of the Scientific Medical Societies in Germany. Eur J Anaesthesiol 33:488-521. https://doi.org/10.1097/EJA. 0000000000000447

3. Goedje O, Seebauer T, Peyerl M et al (2000) Hemodynamic monitoring by double-indicator dilution technique in patients after orthotopic heart transplantation. Chest 118:775-781. https://doi.org/10.1378/chest.118.3.775

4. Michard F, Alaya S, Zarka V et al (2003) Global end-diastolic volume as an indicator of cardiac preload in patients with septic shock. Chest 124:1900-1908. https://doi.org/10.1378/chest.124.5.1900

5. Goepfert MS, Richter HP, Zu Eulenburg C et al (2013) Individually optimized hemodynamic therapy reduces complications and length of stay in the intensive care unit: a prospective, randomized controlled trial. Anesthesiology 119:824-836. https://doi.org/10.1097/ALN.0b013e31829bd770

6. Kaneko T, Kawamura Y, Maekawa T et al (2014) Global end-diastolic volume is an important contributor to increased extravascular lung water in patients with acute lung injury and acuterespiratory distress syndrome: a multicenter observational study. J Intensive Care 2:25. https://doi.org/10.1186/2052-0492-2-25

7. Hilty MP, Franzen DP, Wyss C et al (2017) Validation of transpulmonary thermodilution variables in hemodynamically stable patients with heart diseases. Ann Intensive Care 7:86. https://doi.org/10.1186/s13613-017-0307-0

8. Eichhorn V, Goepfert MS, Eulenburg C et al (2012) Comparison of values in critically ill patients for global end-diastolic volume and extravascular lung water measured by transcardiopulmonary thermodilution: a metaanalysis of the literature. Med Intensiva 36:467-474. https://doi.org/10.1016/j.medin.2011.11.014

9. Huber W, Mair S, Götz SQ et al (2017) A systematic database-derived approach to improve indexation of transpulmonary thermodilution-derived global end-diastolic volume. J Clin Monit Comput 31:143-151. https://doi.org/ 10.1007/s10877-016-9833-9

10. Wolf S, Riess A, Landscheidt JF et al (2009) Global end-diastolic volume acquired by transpulmonary thermodilution depends on age and gender in awake and spontaneously breathing patients. Crit Care 13:R202. https://doi.org/10.1186/cc8209

11. Mao SS, Ahmadi N, Shah B, et al (2008) Normal thoracic aorta diameter on cardiac computed tomography in healthy asymptomatic adults: impact of age and gender. Acad Radiol 15:827-834. https://doi.org/PMC2577848

12. Sakka SG, Meier-Hellmann A (2001) Extremely high values of intrathoracic blood volume in critically ill patients. Intensive Care Med 27:1677-1678. https://doi.org/10.1007/s001340101071

13. Newman EV, Merrell M, Genecin A et al (1951) The dye dilution method for describing the central circulation. Circulation 4:735-746

14. Meier P, Zierler KL (1954) On the theory of the indicator-dilution method for measurement of blood flow and volume. J Appl Physiol 6:731-744

15. Isakow W, Schuster DP (2006) Extravascular lung water measurements and hemodynamic monitoring in the critically ill: bedside alternatives to the pulmonary artery catheter. Am J Physiol Lung Cell Mol Physiol 291:L1118-L1131. https://doi. org/10.1152/ajplung.00277.2006

16. Brown LM, Liu KD, Matthay MA (2009) Measurement of extravascular lung water using the single indicator method in patients: research and potential clinical value. Am J Physiol Lung Cell Mol Physiol 297:L547-L558. https://doi.org/10. 1152/ajplung.00127.2009

17. Stewart GN (1921) The pulmonary circulation time, the quantity of blood in the lungs and the output of the heart. Am J Physiol 58:20-44

18. Effros RM, Pornsuriyasak P, Porszasz J, Casaburi R (2008) Indicator dilution measurements of extravascular lung water: basic assumptions and observations. Am J Physiol Lung Cell Mol Physiol 294:L1023-L1031. https://doi.org/10.1152/ ajplung.00533.2007

19. Monnet $X$, Persichini R, Ktari M et al (2011) Precision of the transpulmonary thermodilution measurements. Crit Care 15: R204. https://doi.org/10.1186/cc10421

20. Ratib O, Rosset A, Heuberger I (2009) OsiriX - The Pocket Guide. Pixmeo SARL, Bernex, Switzerland

21. Setacci $F$, Sirignano $P$, Cappelli A, Setacci $C$ (2012) The wonders of a newly available post-analysis $C T$ software in the hands of vascular surgeons. Eur J Vasc Endovasc Surg 43:404-406. https://doi.org/10.1016/j.ejvs.2011.11.027

22. Akaike $H$ (1974) A new look at the statistical model identification. Autom Control IEEE Trans On 19:716-723

23. Schmidt S, Westhoff TH, Hofmann C et al (2007) Effect of the venous catheter site on transpulmonary thermodilution measurement variables. Crit Care Med 35:783-786. https://doi.org/10.1097/01.CCM.0000256720 $11360 . \mathrm{FB}$

24. Saugel B, Umgelter A, Schuster T et al (2010) Transpulmonary thermodilution using femoral indicator injection: a prospective trial in patients with a femoral and a jugular central venous catheter. Crit Care 14:R95. https://doi. org/10.1186/cc9030

25. Huber W. Phillip V, Höllthaler J et al (2016) Femoral indicator injection for transpulmonary thermodilution using the

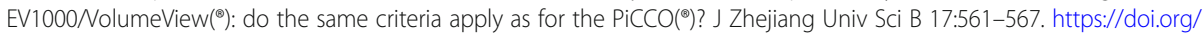
10.1631/jzus.B1500244

26. den Hartog AW, Franken R, de Witte P et al (2013) Aortic disease in patients with Marfan syndrome: aortic volume assessment for surveillance. Radiology 269:370-377. https://doi.org/10.1148/radiol.13122310

27. Rylski B, Desjardins B, Moser W et al (2014) Gender-related changes in aortic geometry throughout life. Eur J Cardiothorac Surg 45:805-811. https://doi.org/10.1093/ejcts/ezt597

28. Chan SK, Jaffer FA, Botnar RM et al (2001) Scan reproducibility of magnetic resonance imaging assessment of aortic atherosclerosis burden. J Cardiovasc Magn Reson 3:331-338 
29. Hager A, Kaemmerer H, Rapp-Bernhardt U, et al (2002) Diameters of the thoracic aorta throughout life as measured with helical computed tomography. J Thorac Cardiovasc Surg 123:1060-1066. https://doi.org/12063451

30. Fleischmann D, Hastie TJ, Dannegger FC et al (2001) Quantitative determination of age-related geometric changes in the normal abdominal aorta. J Vasc Surg 33:97-105 https://doi.org/11137929

31. Kilner PJ, Yang GZ, Mohiaddin RH et al (1993) Helical and retrograde secondary flow patterns in the aortic arch studied by three-directional magnetic resonance velocity mapping. Circulation 88:2235-2247

32. Bogren $\mathrm{HG}$, Buonocore $\mathrm{MH}$, Valente RJ (2004) Four-dimensional magnetic resonance velocity mapping of blood flow patterns in the aorta in patients with atherosclerotic coronary artery disease compared to age-matched normal subjects. J Magn Reson Imaging 19:417-427. https://doi.org/10.1002/jmri.20018

33. Liu X, Sun A, Fan Y, Deng X (2015) Physiological significance of helical flow in the arterial system and its potential clinical applications. Ann Biomed Eng 43:3-15. https://doi.org/10.1007/s10439-014-1097-2

34. Tanner JM (1949) Fallacy of per-weight and per-surface area standards, and their relation to spurious correlation. J Appl Physiol 2:1-15

35. Turner ST, Reilly SL (1995) Fallacy of indexing renal and systemic hemodynamic measurements for body surface area. Am J Physiol 268:R978-R988

36. Dewey FE, Rosenthal D, Murphy DJ et al (2008) Does size matter? Clinical applications of scaling cardiac size and function for body size. Circulation 117:2279-2287. https://doi.org/10.1161/CIRCULATIONAHA.107.736785

37. Bilgin S, Topal FE, Yamanoğlu A et al (2019) Effect of changes in intravascular volume on inferior vena cava and aorta diameters and the caval/aorta index in healthy volunteers. J Ultrasound Med Off J Am Inst Ultrasound Med. https://doi. org/10.1002/jum.15093

38. Akohov A et al, "Aortic volume and GEDV - individual patient data", Zenodo Data Repository, www.zenodo.org, deposit 3378028

\section{Publisher's Note}

Springer Nature remains neutral with regard to jurisdictional claims in published maps and institutional affiliations.

\section{Submit your manuscript to a SpringerOpen ${ }^{\circ}$ journal and benefit from:}

- Convenient online submission

- Rigorous peer review

Open access: articles freely available online

High visibility within the field

Retaining the copyright to your article

Submit your next manuscript at $>$ springeropen.com 